\title{
Comparison of Nutrient Content in Acid Treated Fish Waste Compost with Normal Fish Waste Compost
}

\author{
D.T. Gunawardana, M.K.T.K. Amarasinghe, H.K.M.S. Kumarasinghe, \\ G.A.H.Galahitigama* \\ Department of Crop Science, Faculty of Agriculture, University of Ruhuna, Sri Lanka \\ *hgalahitigama@gmail.com
}

\begin{abstract}
Fish waste management is one of the main problems in fishing industry which can be possible to eliminate through making compost. Though nutrient content is high in fish waste and most of the nutrients are removed from final product during composting process due to low decomposition rate. The present study was carried out to increase decomposition rate by adding different additives to fish waste compost at International Food Stuff Company Farm at Kamburupitiya in October 2014. Pit method was used for making compost and two additives, i.e., sulfuric acid and citric acid were used with two concentrations $(0.5 \mathrm{ppm}$ and $1.0 \mathrm{ppm})$. Five treatments i.e., fish waste compost treated with $1.0 \mathrm{ppm}$ sulfuric acid $\left(\mathrm{T}_{1}\right)$, fish waste compost treated with $0.5 \mathrm{ppm}$ sulfuric acid $\left(\mathrm{T}_{2}\right)$, fish waste compost treated with water (control) $\left(\mathrm{T}_{3}\right)$, fish waste compost treated with $0.5 \mathrm{ppm}$ citric acid $\left(\mathrm{T}_{4}\right)$ and fish waste compost treated with $1.0 \mathrm{ppm}$ citric acid $\left(\mathrm{T}_{5}\right)$ were used as treatments and pits were arranged in complete randomised block design (RCBD) with tri-replicates. Temperature, pH, EC, nitrogen, phosphorous, potassium and particle size distribution of end product was taken as variables. Data were analysed using ANOVA. Fish waste compost treated with water showed maximum temperature within three days time while acid treated fish waste composts $\left(\mathrm{T}_{1}, \mathrm{~T} 2, \mathrm{~T} 4\right.$ and $\left.\mathrm{T}_{5}\right)$ took five days time to reach their maximum temperature.1.0 ppm sulfuric acid treated fish waste compost showed significantly lower $(\mathrm{P}<0.05) \mathrm{pH}$ value than all other treatments while $\mathrm{pH}$ ranges from 5.4 to 6.5 in all the treatments. Significantly higher $(\mathrm{P}<0.05)$ EC value $(961 \mu \mathrm{s} / \mathrm{cm})$ was in acid treated fish waste compost and lowest value $(583 \mu \mathrm{s} / \mathrm{cm})$ was in control treatment. Significantly higher $(\mathrm{P}<0.05)$ nitrogen content $(0.5016 \mathrm{~g} / \mathrm{kg})$ was recorded in $\mathrm{T}_{1}$ followed by fish waste compost treated with others $\left(\mathrm{T}_{1}, \mathrm{~T} 2, \mathrm{~T} 4\right.$ and $\left.\mathrm{T}_{5}\right)$ respectively. Fish waste compost treated with $1 \mathrm{ppm}$ sulfuric acid showed significantly higher phosphorous concentration $(46.4 \mathrm{ppm})$ while $\mathrm{T}_{3}$ showed significantly lower phosphorous (35.62 ppm). With regard to phosphorous, there was no significant difference among all other acid treated fish waste compost was detected. Compared to all acid treated fish waste compost potassium concentration was higher in control treatment (36.40 ppm). There was no significant difference in particle size distribution of all the treatments was detected. Acid treatment showed positive effect on nitrogen and phosphorous availability while negative effect on potassium availability of fish waste compost. This trend increased with the increment of the concentration of acid. Among the different fish waste compost mixtures, 1.0 ppm sulfuric treated fish waste compost showed higher $\mathrm{N}$ and $\mathrm{P}$ content and low $\mathrm{K}$ content with better $\mathrm{pH}$ and EC values compared to all other treatments. Therefore, $1.0 \mathrm{ppm}$ sulfuric acid could be used as additive for treating fish waste compost.
\end{abstract}

Keywords: Fish waste, Compost

Proceedings of the International Forestry and Environment Symposium 2015 of the Department of Forestry and Environmental Science, University of Sri Jayewardenepura, Sri Lanka 